\title{
DEVELOPMENT OF A VESSEL MIMICKING MATERIAL FOR USE IN ANATOMICALLY REALISTIC DOPPLER FLOW PHANTOMS
}

D M King ${ }^{*}$, C M Moran†, J D McNamara ${ }^{*}$, A J Fagan ${ }^{* *}$ and J E Browne*

* Medical Ultrasound Physics and Technology Group, School of Physics and FOCAS

Institute, Dublin Institute of Technology, Dublin, Ireland

${ }^{\dagger}$ Medical Physics Unit, University of Edinburgh, Edinburgh, UK

$\$$ School of Manufacturing and Design and the Centre for Elastomer Research Dublin Institute of Technology, Dublin, Ireland

${ }^{* *}$ Centre for Advanced Medical Imaging, St James’s Hospital, Dublin 8, Ireland

Corresponding author

Dr Jacinta Browne,

Medical Ultrasound Physics and Technology Group,

School of Physics,

Dublin Institute of Technology,

Kevin Street,

Dublin 8,

Ireland.

E-mail: jacinta.browne@dit.ie 


\title{
DEVELOPMENT OF A VESSEL MIMICKING MATERIAL FOR USE IN
}

\section{ANATOMICALLY REALISTIC DOPPLER FLOW PHANTOMS}

\begin{abstract}
Polyvinyl alcohol cryogel, (PVA-C) is presented as a vessel mimicking material for use in anatomically realistic Doppler flow phantoms. Three different batches of $10 \%$ wt PVA-C containing (i) PVA-C alone, (ii) PVA-C with anti-bacterial agent and (iii) PVA-C with silicon carbide particles were produced, each with 1 to 6 freeze-thaw cycles. The resulting PVA-C samples were characterized acoustically (over a range $2.65-10.5 \mathrm{MHz}$ ) and mechanically in order to determine the optimum mixture and preparation for mimicking the properties of healthy and diseased arteries found in vivo. This optimum mix was reached with the PVA-C with anti-bacterial agent sample, prepared after 2 freeze/thaw cycles, which achieved a speed of sound of $1538 \pm 5 \mathrm{~m} \mathrm{~s}^{-1}$ and a Young's elastic modulus of $79 \pm 11 \mathrm{kPa}$. This material was used to make a range of anatomically-realistic flow phantoms with varying degrees of stenoses, and subsequent flow experiments revealed that higher degrees of stenoses and higher velocities could be achieved without phantom rupturing compared to a phantom containing conventional wall-less vessels.
\end{abstract}

\section{Keywords}

Polyvinyl alcohol cryogel, vessel mimic, ultrasound phantom, anatomically realistic flow phantom, acoustic and mechanical characterisation 


\section{Introduction}

In vitro flow phantoms have been used as quality assurance and performance testing tools since the late 1980s and have been reviewed by Law et al. (1989). Since the 1990s, anatomically-realistic in vitro flow phantoms have also been developed for use in the area of blood flow investigation, although most of these phantoms have concentrated on replicating the carotid artery (see the recent review of Hoskins 2008). These phantoms consist of a tissue mimicking material (TMM) surrounding a vessel through which a blood-mimicking fluid (BMF) is pumped, with the flow of BMF through the phantom being either steady or pulsatile (Shortland and Cochrane 1989). An important criterion for such a phantom is that the individual components used in their construction should have similar acoustic and mechanical properties to soft tissue, vessel tissue and blood, in order to avoid artifacts and allow for meaningful quality assurance and blood flow measurements to be made.

A range of materials have been used to mimic the vessel wall in these flow phantoms including: glass, plastic, Teflon, latex, C-flex, heat shrink and neoprene, often chosen due to their availability in tube form (Law et al. 1989; IPEM 1994; Hoskins 2008). The material C-flex (Cole-Parmer, Walden, UK) is one of the more commonly used materials, however, it tends to produce significant distortion of the Doppler spectrum due to its very high attenuation coefficient (Teirlinck, Bezemer et al. 1998), and it has a reported speed of sound and attenuation of $1557 \mathrm{~m} \mathrm{~s}^{-1}$ and $58 \mathrm{~dB} \mathrm{~cm}^{-1}$, respectively, at $8 \mathrm{MHz}$ (IPEM 1994). Furthermore, this material is only commercially available with fixed dimensions and consequently it is not suitable for use in mimicking the complex vessel shapes (complete with curvatures, blockages, etc) which are required in an anatomically realistic flow phantom. To overcome this problem, some researchers have used excised human vessels removed during either autopsy or endarterectomy, (Dabrowski et al. 1997; Dabrowski et al. 2001; BaleGlickman et al. 2003). However, this method is not ideal due to the associated ethical issues 
surrounding the use of ex vivo human tissue, together with the limited long-term stability of phantoms made using such materials and the problem of reproducing such a phantom due to the unique nature of the particular vessel used in its construction.

Another approach to the development of anatomically realistic flow phantoms is to develop phantoms with no vessel walls, known as "wall-less" flow phantoms. In this case, the BMF is in direct contact with the TMM (Rickey et al. 1995; Ramnarine et al. 2001). Wall-less flow phantoms resolve the problem of the high attenuation of conventionally-used materials used to mimic the vessel walls, and also make it possible to produce a variety of vessel geometries, such as bends, bifurcations and stenosed lumens. However, these phantoms tend to rupture when used under physiological flow conditions, particularly when a high degree of stenosis is present in the phantom (Meagher et al. 2007), and thus their use for investigating many clinically relevant pathologies is severely limited.

The ideal solution lies in the development of a vessel wall mimicking material (VMM), with sufficient strength to withstand high flow rates and flexibility in construction to model complex shapes, but which also mimics the acoustic and mechanical properties of human arteries. However, work in this area is limited (Poepping et al. 2004; Surry et al. 2004; Dineley et al. 2006). Furthermore, although the International Electrotechnical Commission (IEC) publish specifications for the required properties of TMMs (IEC 2001), there are no separate specifications for the properties of VMMs.

There is growing interest in the use of Polyvinyl Alcohol Cryogel (PVA-C) to mimic a range of tissue properties for applications in magnetic resonance imaging (MRI) (Chu and Rutt 1997) and ultrasound (Cournane et al 2010; Dineley et al, 2006; Surry et al 2004)), where the large effects of varying the concentration of PVA-C powder or the number and/or timing of the freeze/thaw cycles used in its preparation can be exploited to tweak the properties of the resulting material to suit the application. From an ultrasound perspective, a 
particular problem with the use of PVA-C lies in its low acoustic attenuation coefficient, although this shortcoming has been resolved through the addition of enamel paint or particles such as silicon carbide to the mix (Surry et al. 2004; Dineley et al. 2006). Another feature of PVA-C is that it is hydrophilic and if exposed to air there is a possibility that bacterial growth can occur. It is therefore advantageous to add an anti-bacterial agent to the PVA-C which can help to increase the lifetime of the sample. Chu and Rutt (1997) stated that the addition of an anti-bacterial agent changes the VMM properties slightly but no data was presented to support this statement. The acoustic and mechanical properties of a range of PVA-C samples reported in the literature for use as a VMM are presented in Table 1, together with typical values for human soft tissue and aorta. The large variation in results across these publications reflects the different manufacturing recipe used in each study, and to date no one study has systematically investigated the effect of varying each of these parameters on the resulting properties, with a view to optimizing the manufacturing steps required to produce an optimal set of acoustic and mechanical properties for use as a VMM.

Table 1. Acoustic and mechanical properties of PVA-C and ex vivo tissues.

\begin{tabular}{cccc}
\hline & $\begin{array}{c}\text { Speed of sound } \\
\left(\mathbf{m ~ s}^{-\mathbf{1}}\right)\end{array}$ & $\begin{array}{c}\text { Attenuation } \\
\text { Coefficient } \\
\left(\mathbf{d B ~ c m}^{-\mathbf{1}} \mathbf{~ M H z}^{-\mathbf{1}}\right)\end{array}$ & $\begin{array}{c}\text { Young's Modulus } \\
\mathbf{( k P a )}\end{array}$ \\
\hline Soft tissue & $1540^{*}$ & $0.3-0.6^{*}$ & \\
Aorta (human) & $1501-1534^{\dagger}, 1616^{*}$ & 0.6 at $10 \mathrm{MHz}{ }^{\dagger}$ & $70-100^{\ddagger}$ \\
PVA-C (5\%) & $1505-1506^{\S \S}$ & $0.13-0.67$ at $7 \mathrm{MHz}^{\S \S}$ & $2.5-5.4^{\S \S}$ \\
PVA-C (10\%) & $1522-1545^{\S}$ & $0.5-1.0^{\S}$ & $24-135^{\|}$ \\
PVA-C (15\%) & $1546-1584^{* *}$ & $0.2-0.4^{* *}$ & $190-1840^{\dagger \dagger}$ \\
\hline
\end{tabular}

* (Duck 1990), ${ }^{\dagger}$ (Greenleaf et al., 1974) ${ }^{\ddagger}{ }^{\dagger}$ (Kawasaki et al. 1987), ${ }^{\S}$ (Surry et al. 2004), "(Duboeuf et al. 2007), ${ }^{* *}$ (Dineley et al. 2006), ${ }^{\dagger \dagger}$ (Chu and Rutt 1997), ${ }^{\S \S}$ Cournane et al. 2010 
The current study aimed to investigate the effect of systematically varying the number of freeze/thaw cycles on a range of samples containing PVA-C alone, PVA-C containing an anti-bacterial agent, and PVA-C which contained silicon carbide particles with/without the anti-bacterial agent. The viscoelastic behavior of the optimum preparation thus determined was then investigated. Finally, this material was used to construct a range of walled anatomically-realistic flow phantoms with varying degrees of stenoses, which were compared to a second range of phantoms constructed using a wall-less vessel approach. 


\section{Materials and Methods}

PVA-C sample preparation

Three batches of PVA-C were produced (PVAGELS, Kingston, NY, USA):

Batch-1: A $10 \%$ wt PVA gel in water was prepared by heating the gel and water mixture in a sealed container in a water bath at $100 \pm 1^{\circ} \mathrm{C}$ for 60 minutes.

Batch-2: A second batch of PVA-C was prepared with the addition of an anti-bacterial agent Benzalkonium Chloride (BC) (Quatachem Ltd, Oldham, UK) in order to investigate the effect of the anti-bacterial agent on the acoustic properties. This batch was divided into three groups containing $\mathrm{BC}$ concentrations of $0.46 \% \mathrm{wt}, 0.92 \%$ wt and $1.40 \%$ wt which were added to the liquefied PVA and slowly rotated to ensure even distribution.

Batch-3: A third batch of PVA-C was prepared with the addition of $17 \mu \mathrm{m}$ silicon carbide particles (Logitech, Glasgow, UK) in order to increase the acoustic attenuation of the sample. This batch was divided into two groups: one containing only the silicon carbide particles $(0.75 \% \mathrm{wt})$ and the second containing both the silicon carbide and the anti-bacterial agent (0.75\% wt SiC and $0.46 \%$ wt BC). Care was taken when adding the silicon carbide particles to avoid clumping.

The PVA-C solutions were allowed to cool to $50{ }^{\circ} \mathrm{C}$ at which point $15 \mathrm{ml}$ of liquefied PVA was injected into a Petri dish $(50 \times 15 \mathrm{~mm})$ for acoustical testing. The Petri dishes were sealed with Parafilm ${ }^{\circledR}$ M (Pechiney Plastic Packaging, Il, USA) with $10 \%$ volume left for expansion during the freezing stage, and left to stand upright for 8 hours to allow air bubbles to rise to the surface. In addition, to produce sample strips suitable for mechanical and viscoelastic testing, at $50{ }^{\circ} \mathrm{C}$ liquefied PVA-C $(15 \mathrm{ml})$ was slowly injected into a custommade rectangular aluminum mould containing wells measuring $100 \mathrm{~mm} \times 10 \mathrm{~mm} \times 3 \mathrm{~mm}$. The wells were sealed by screwing an aluminum lid onto the lower section. The mould 
assembly was allowed to stand for 24 hours at room temperature $\left(22 \pm 0.5^{\circ} \mathrm{C}\right)$ so that any air bubbles present could rise to the top of the sample. For the viscoelastic testing, uniaxial S2 samples (as defined in ISO-7743) were cut from the sheets produced by the rectangular aluminium mould of PVA-C $+\mathrm{BC}$ (Batch 2) material using a S2 specimen stamp. These samples were $2 \mathrm{~mm}$ thick with a gauge length of $20 \mathrm{~mm}$.

Following the settle time, the moulds were placed in a freezer at $-20{ }^{\circ} \mathrm{C}$ for 14 hours after which they were allowed to thaw at room temperature $\left(22 \pm 0.5^{\circ} \mathrm{C}\right)$ for 10 hours. This step was counted as the first freeze-thaw cycle. From previous studies it was decided that 1 6 freeze-thaw cycles were sufficient to obtain the desired range of acoustic and mechanical properties similar to in vivo arteries (Surry et al. 2004; Dineley et al. 2006). The first batch (Batch-1) was sub-divided into six groups depending on the number of freeze-thaw cycles used (1 - 6), while Batch-2 and Batch-3 were divided into three groups corresponding to 2, 4 and 6 freeze-thaw cycles. Once the required number of freeze-thaw cycles was completed, the samples were removed from their moulds and stored in de-ionized water at $5{ }^{\circ} \mathrm{C}$ to prevent dehydration.

\section{Acoustic Characterization}

The speed of sound $(c)$ and attenuation coefficient $(\alpha)$ of the three batches of PVA-C samples were determined using a scanning acoustic macroscope (SAM) system (Ultrasonic Sciences Limited, Fleet, UK), as follows. The pulse-echo substitution method was used, wherein the pulse was transmitted through the surrounding medium (degassed water at room temperature and sample if present) and reflected from a highly polished flat steel plate. All measurements data were collected and averaged over a $256 \mathrm{~mm}^{2}$ area of the sample. Two different transducers were used in this study, one operating at 3.5 MHz (Ultrasonic Sciences Limited, Fleet, UK) and a second at $7 \mathrm{MHz}$ (Panametrics, Olympus, MA, USA), with each acting as 
both as a transmitter and receiver with frequency ranges of $2.65-5.12 \mathrm{MHz}$ and $5.5-$ 10.5 MHz, and focal depth 58 and $54 \mathrm{~mm}$, respectively. All acoustic measurements were carried out in a temperature-monitored water tank. Degassed water was poured into the tank at least 3 hours prior to measurement to allow the set-up to reach thermal equilibrium with its surroundings. Immediately prior to each measurement, the submerged transducer face was inspected for air bubbles. If air bubbles were present they were removed by syringing water across the face of the transducer. A highly polished steel reflector was placed in the focus of the transducer. The transducer performed two raster scans each with a scan area $16 \times 16 \mathrm{~mm}^{2}$ with $1 \mathrm{~mm}$ increments in each direction; the first scan served as a reference scan, comprising only the steel reflector in the beam, while the second scan included the sample placed on top of the steel reflector. At each position of the transducer, the reflected RF signal from the steel reflector was digitised at a sampling rate of $100 \mathrm{MHz}$ and stored for off-line analysis.

The speed of sound and attenuation coefficient of the samples was determined by comparing the resulting frequency spectra measured with and without the sample in place. The speed of sound and attenuation coefficient for each sample was calculated as described by Browne et al. (2003). For speed of sound measurements, the systematic error was estimated to be $0.8 \mathrm{~m} \mathrm{~s}^{-1}$, determined from uncertainties in the path length, the sample thickness, the definition of the pulse arrival time, and the speed of sound within the reference medium (water), while the random uncertainty was estimated to be $\pm 0.5 \mathrm{~m} \mathrm{~s}^{-1}$, determined from repeat measurements from a reference water path scan. Inhomogeneity of the PVA-C samples due to cross-linking led to an estimated uncertainty in repeat measurements of \pm $5 \mathrm{~m} \mathrm{~s}^{-1}$. This uncertainty dominated the overall error associated with the measurement of speed of sound. The accuracy of the attenuation measurements using the SAM system was previously estimated to be $\pm 0.03 \mathrm{~dB} \mathrm{~cm}^{-1}$ due to a random error of $\pm 0.02 \mathrm{~dB} \mathrm{~cm}^{-1}$ and a systematic error of $\pm 5 \%$ Browne et al. (2003). The systematic error was due to reflection, 
diffraction, alignment of the transducer, and uncertainty in the measurement of the sample thickness.

\section{Mechanical Characterization}

Measurement of Young's Elastic Modulus of the PVA-C samples. Uniaxial tensile testing was performed using a LR30K tensile testing system (Lloyd Instruments Ltd, Hamshire, U.K.) fitted with a $500 \mathrm{~N}$ load cell. All mechanical tests were carried out at room temperature, $22 \pm 0.5^{\circ}$ C. Preliminary tests were carried out to investigate if the PVA-C + BC (Batch 2) material exhibited a feed rate dependency. Three different feed rates, 5, 10 and $50 \mathrm{~mm} \mathrm{m^{-1 }}$ were used on the PVA-C $+\mathrm{BC}$ (Batch 2) test strips which had undergone 6 freeze-thaw cycles. The samples were loaded at the three feed rates to a maximum displacement of $80 \%$ of the gauge length. No significant difference in the behaviour of the PVA-C $+\mathrm{BC}$ test strips was evident, indicating that the modulus of the material did not exhibit rate dependency. This allowed the higher feed rate of $50 \mathrm{~mm} / \mathrm{min}$ to be used for subsequent experiments, reducing the overall experimental time. The PVA-C $+\mathrm{BC}$ test strips were fixed between tensile grips and the distance between the two opposing grips was $60 \mathrm{~mm}$; this was taken as the gauge length. Each of the PVA-C + BC test strips which had undergone 2, 4 or 6 freezethaw cycles were subjected to 5 stress-strain cycles to a maximum displacement of $80 \%$ of the gauge length. A minimum load of $0.01 \mathrm{~N}$ was maintained to prevent buckling of the PVA-C + BC test strip when it approached the zero strain position. To prevent dehydration of the samples during testing, de-ionized water was sprayed onto the test strips while they were secured in the test rig and when undergoing cyclic deformation. Raw data in the form of load-extension curves were converted into engineering stress and engineering strain using the initial gauge length and sample dimensions. The Young's elastic moduli were calculated 
from the upward loading portion of the $5^{\text {th }}$ stress strain cycle in accordance with the international standard (ISO-7743 2008). The modulus was evaluated as the mean gradient of the best fit least squares line to the data from $0-30 \%$ strain where the behaviour was linear. This corresponded to a stress of $50 \mathrm{kPa}$ which is much higher than the stress that may be experienced in vivo for example the intraluminal pressure which is approximately $19 \mathrm{kPa}$ (Poepping et al. 2004 and Dineley et al. 2006).

Measurement of Viscoelastic Properties of PVA-C + BC (Batch 2) samples. In order to characterize the viscoelastic properties a Zwick tensile testing machine (Type 1445.17, Zwick GmbH \& Co. KG, Ulm, Germany) was used. The strain applied to the uniaxial S2-shaped PVA-C + BC samples was optically measured using the extensometer on the Zwick tensile testing machine by tracking the two reflective points to the sample. The system was fitted with a $50 \mathrm{~N}$ load cell and a comprehensive uniaxial test protocol was developed which incorporated methodology utilized by Wan et al. (2002), Dineley et al. (2006) and Fromageau et al. (2007) to mechanically characterize the PVA-C samples. A feed rate of 5 $\mathrm{mm} \mathrm{min}^{-1}$, which was common to all three studies, was selected and the samples prepared from each freeze-thaw cycle were subjected to 6 stress strain cycles to a maximum displacement of $80 \%$ of the gauge length. Once again, a minimum load of $0.01 \mathrm{~N}$ was maintained to prevent buckling of the sample when it was close to the zero strain position. The first 5 stress strain cycles were applied to condition the material and to investigate any hysteresis effects as the cross-linked network was broken down with successive cyclic loading. The $6^{\text {th }}$ stress strain cycle was used to measure the stress relaxation effects common to viscoelastic materials by incorporating a pause at the maximum strain of $80 \%$ of the gauge length for a period of 100 seconds before the sample was returned to its minimum load position. 
Basic flow simulations

To demonstrate the viability of the Batch 2 PVA-C material at $2 \mathrm{f} / \mathrm{t}$ cycles $(\mathrm{PVA}-\mathrm{C}+\mathrm{BC}$ ) as a vessel mimic, two types of anatomically realistic renal artery phantoms (a wall-less flow phantom and a walled flow phantom, walled composed of PVA-C+BC $(0.46 \mathrm{wt} \%)$ after $2 \mathrm{f} / \mathrm{t}$ cycles vessel mimicking material) were fabricated and tested with no stenosis present and four degrees of stenoses: $30,50,70$ and $85 \%$. In the wall-less flow phantom, the BMF was in direct contact with the agar based TMM (developed as per Terlinck et al. (1998)), while in the walled flow phantom a vessel wall was between the BMF and the TMM. The vessel geometry used to fabricate these phantoms was based on the anatomically realistic renal artery models previously described by King et al. (2010), where a 3D computer model of a healthy renal artery was generated from a clinical 3D CT dataset using the following procedure: The computer model of the renal artery was exported into a rapid prototyping machine (Model: Z printer 310 Plus 3D, Zcorporation, MA, USA), from which a physical model of the artery was produced with a diameter of $6.8 \mathrm{~mm}$. The physical model thus produced was then used to create a master silicone negative mould, into which a low melting point alloy (melting point: $47{ }^{\circ} \mathrm{C}$, MCP 47, Mining and Chemical Products Ltd., Northamptonshire, UK) was poured. For the walled phantoms, a second silicone negative mould was required which had a diameter equal to the lumen diameter plus the vessel wall thickness. The low-melting-point alloy was then suspended centrally to this second silicon mould, thereby leaving a space surrounding the lumen into which the VMM was injected (Fig. 1). The VMM used was the same preparation of [PVA-C $+\mathrm{BC}]$ gel (Batch 2) was used as described in the Methodology section. Once the VMM was injected, the complete mould assembly underwent 2 freeze/thaw cycles. The assembly was then heated to $50{ }^{\circ} \mathrm{C}$ to remove the metallic alloy, following which the PVA-C $+\mathrm{BC}$ vessel was carefully removed from 
outer silicon mould. The PVA-C $+\mathrm{BC}$ vessels were attached to inlet and outlet tubing (7.9 mm i.d. Nalgene PVC plastic tubing, Thermo Fisher Scientific, NY, USA) on the phantom housing using cable ties. An agar-based tissue mimicking material (TMM) developed by Terlinck et al. (1998) and whose manufacture is described by Ramnarine et al. (2001) was poured around it and allowed to set. During this period, water was pumped through the vessel to prevent it from collapsing.

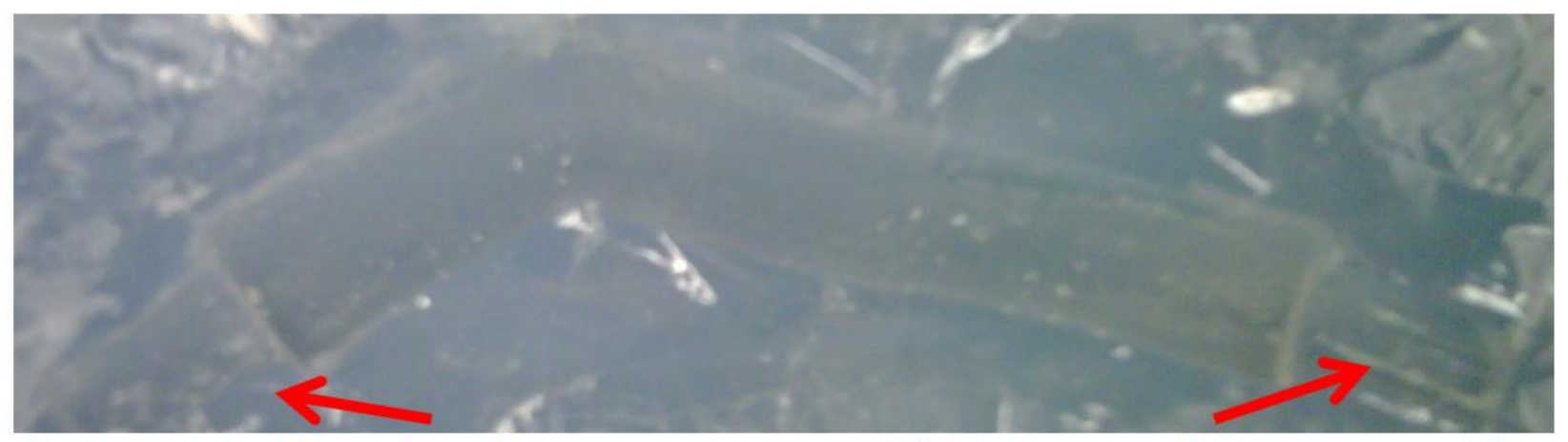

End piece used for positioning the renal artery mould in the centre of the lumen mould

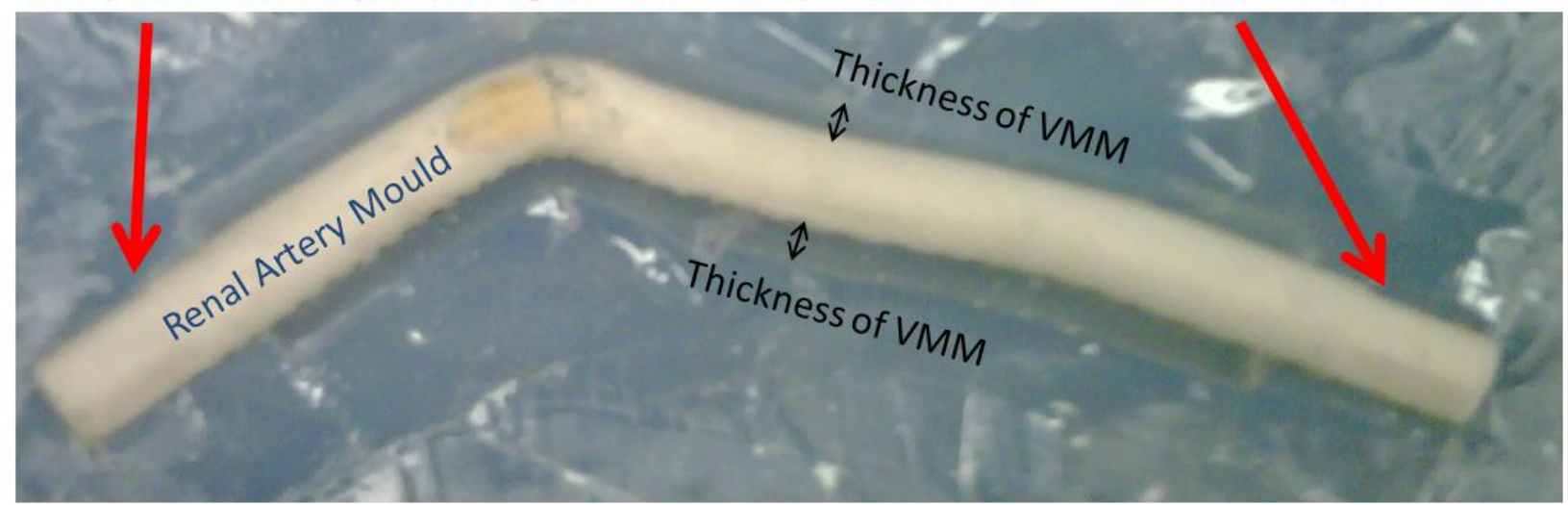

Fig. 1. Photograph of the mould for the producing the vessel mimicking material for the walled anatomically realistic renal artery flow phantoms

The phantoms were connected to an in-house built flow system which provided steady-state flow. The BMF recommended in the IEC specifications and described by Ramnarine et al. (1998) was used. The flow system consisted of a magnetically driven gear pump head (Cole Parmer, Walden, UK) coupled to a direct current servo motor (McLennan Servo Suppliers Ltd., Surrey, UK). The motor was driven by a servo amplifier (Aerotech 
Ltd., Berkshire, UK) and a computer controller program developed in Labview (National Instruments, TX, USA) was used to output mean velocities of $25 \mathrm{~cm} \mathrm{~s}^{-1}$ and $40 \mathrm{~cm} \mathrm{~s}^{-1}$ (calibrated using timed weight collection). As the required inlet length of $26 \mathrm{~cm}$ was used $(\mathrm{L}=0.04 \mathrm{dRe}$, where $\mathrm{L}=$ inlet length, $\mathrm{d}=$ inner diameter and $\mathrm{Re}=$ Reynolds number $)$ it was assumed that the maximum velocity was twice the mean velocity and so the two maximum velocities used in this study were $50 \mathrm{~cm} \mathrm{~s}^{-1}$ and $80 \mathrm{~cm} \mathrm{~s}^{-1}$. BMF which had been degassed using a sonicator was pumped through the phantoms using the gear pump for 1 hour prior to measurements to ensure no air bubbles remained. A HDI 3000 (ATL/Philips, Amsterdam, The Netherlands) with a linear broadband transducer (L12-5), was used to obtain Pulsed Wave Spectral Doppler data along the length of the 50, 70 and $85 \%$ stenosed wall-less and walled renal artery phantoms. 


\section{Results}

PVA-C Acoustic Characterization

For all three PVA-C batches investigated the speed of sound was found to increase with increasing number of freeze-thaw cycles. The speed of sound for the Batch-1 measurement after one freeze-thaw cycle was $1510 \pm 5 \mathrm{~m} \mathrm{~s}^{-1}$ obtained with the $3.5 \mathrm{MHz}$ transducer, which increased by approximately $10 \mathrm{~m} \mathrm{~s}^{-1}$ with each freeze-thaw cycle and reached $1562 \pm 5 \mathrm{~m} \mathrm{~s}^{-1}$ after 6 freeze-thaw cycles. The speed of sound measurements at $7 \mathrm{MHz}$ were found to follow a similar trend, as illustrated in Fig. 2. Also presented in Fig. 2 are data by Surry et al. (2004) who investigated the effect of increasing the number of freeze-thaw cycles of PVA-C (10\% wt) samples on the speed of sound across the frequency range $3-8 \mathrm{MHz}$, and data by Dineley et al. (2007) who investigated the effect of increasing the number of freeze-thaw cycles of PVA-C (15\% wt) samples and the addition of $\mathrm{SiC}$ particles on the speed of sound at $7 \mathrm{MHz}$.

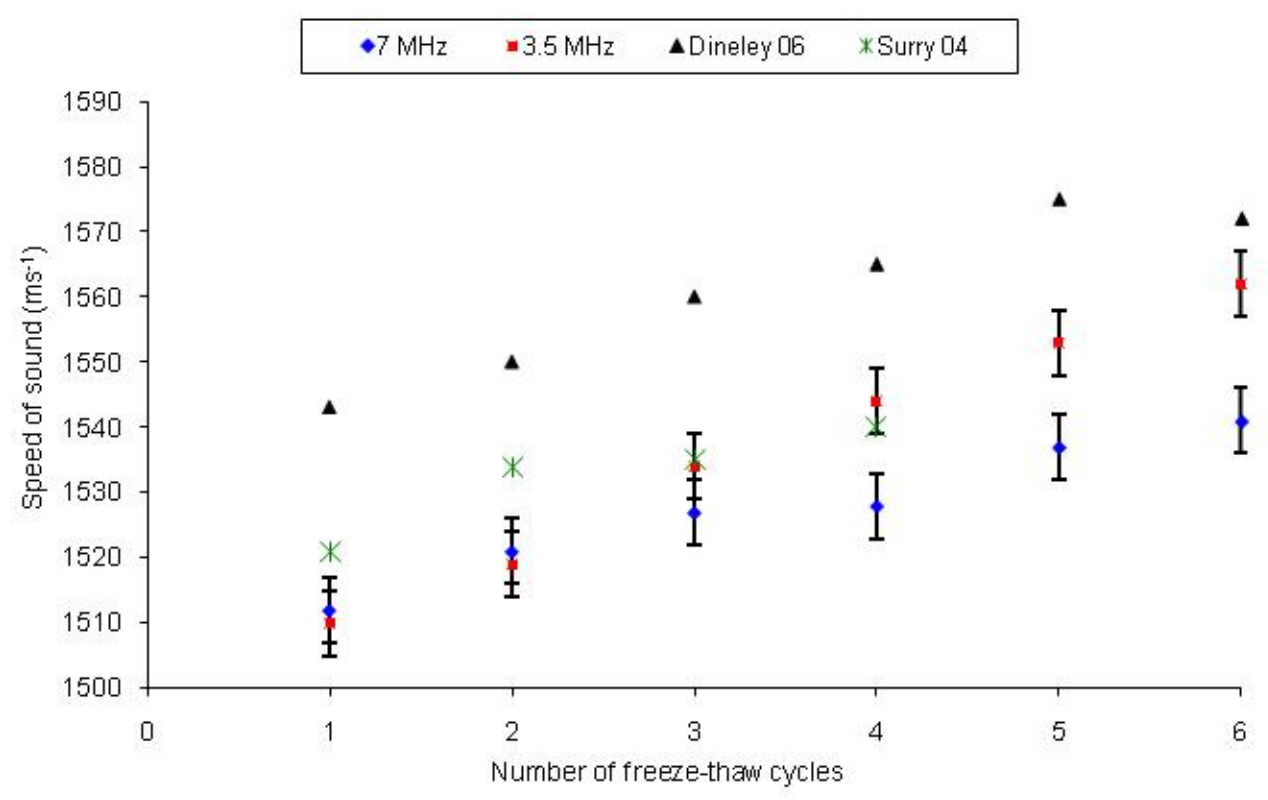


Fig. 2. Effect of increasing the number of freeze-thaw cycles on the speed of sound for $10 \%$ wt PVA-C at both 3.5 and $7 \mathrm{MHz}$ for Batch-1 samples, compared with data from Dineley et al. (2006) at 7MHz and Surry et al. (2004) at $3-8 \mathrm{MHz}$.

The data for the attenuation coefficient from the same batch of samples is presented in Fig. 3, again compared to data from Surry et al. (2004) and Dineley et al. (2007). No significant $(p<0.05)$ increase in the attenuation coefficient was measured using the $3.5 \mathrm{MHz}$ transducer $\left(0.02-0.06 \pm 0.03 \mathrm{~dB} \mathrm{~cm}^{-1} \mathrm{MHz}^{-1}\right)$, while at $7 \mathrm{MHz}$ the attenuation coefficient was found to increase from $0.06-0.30 \pm 0.03 \mathrm{~dB} \mathrm{~cm}^{-1} \mathrm{MHz}^{-1}$ with increasing number of freeze-thaw cycles.

\begin{tabular}{|lll|}
\hline$* 7 \mathrm{MHz}$ & $\quad \mathbf{m} \mathrm{MHz} \quad \Delta$ Dineley 06 $\quad$ *Surry 04 \\
\hline
\end{tabular}

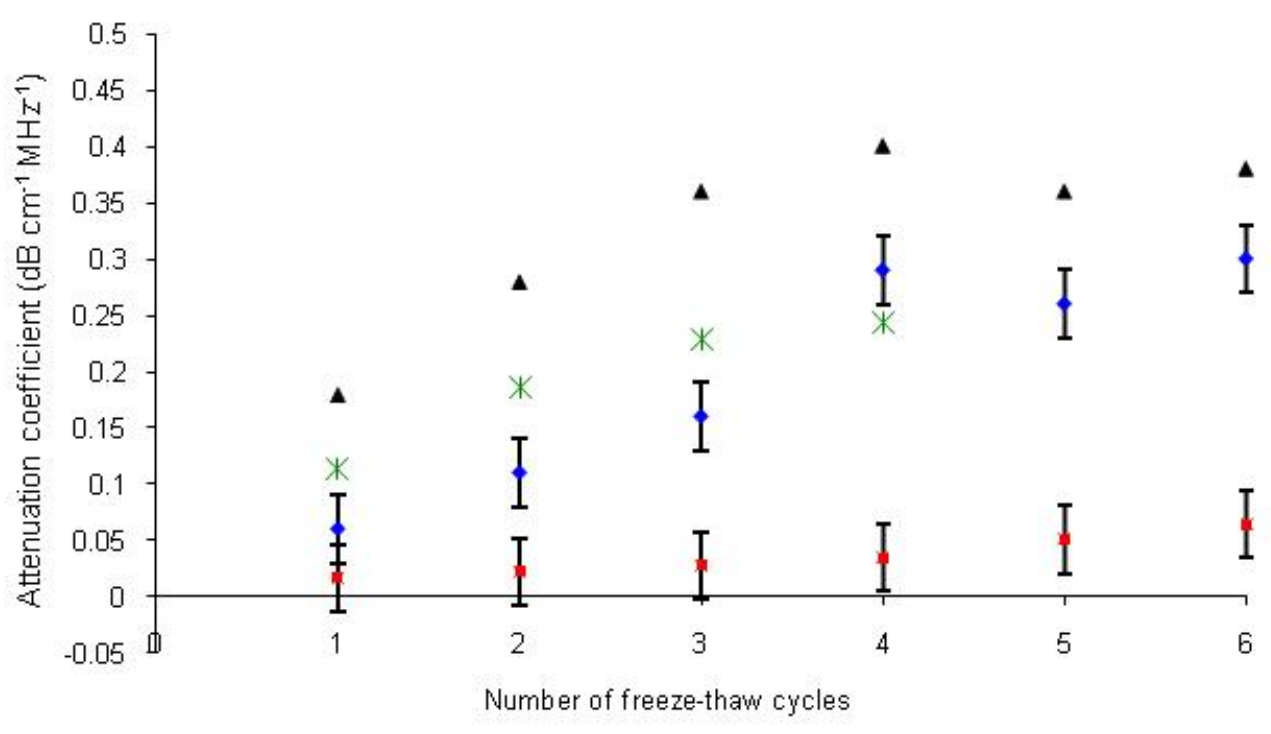

Fig. 3. Effect of increasing the number of freeze-thaw cycles on the attenuation coefficient for $10 \%$ wt PVA-C at both 3.5 and $7 \mathrm{MHz}$ for Batch-1 samples, compared with data from Dineley et al. (2006) at 7MHz and Surry et al. (2004) at $3-8 \mathrm{MHz}$. 
The variation in the attenuation coefficient over a frequency range of $5.5-10.5 \mathrm{MHz}$, measured using the $7 \mathrm{MHz}$ broadband transducer, for increasing numbers of freeze-thaw cycles for the PVA-C samples in Batch-1 is presented in Fig. 4. The attenuation coefficient of all PVA-C samples increased with increasing frequency and increasing number of freezethaw cycles. In each case, the data was fitted to a function of the form $\alpha=a f^{b}$ (the results of the fits are shown in Fig. 4), all of the freeze thaw cycles tested were found to have a linear response of attenuation to frequency with $\mathrm{b}$ values of between 1.0 and 1.1 , this is important as it is recommended in the IEC 2001 standard that such a relationship exists between the attenuation value of the VMM and frequency in the diagnostic range of $2-15 \mathrm{MHz}$.

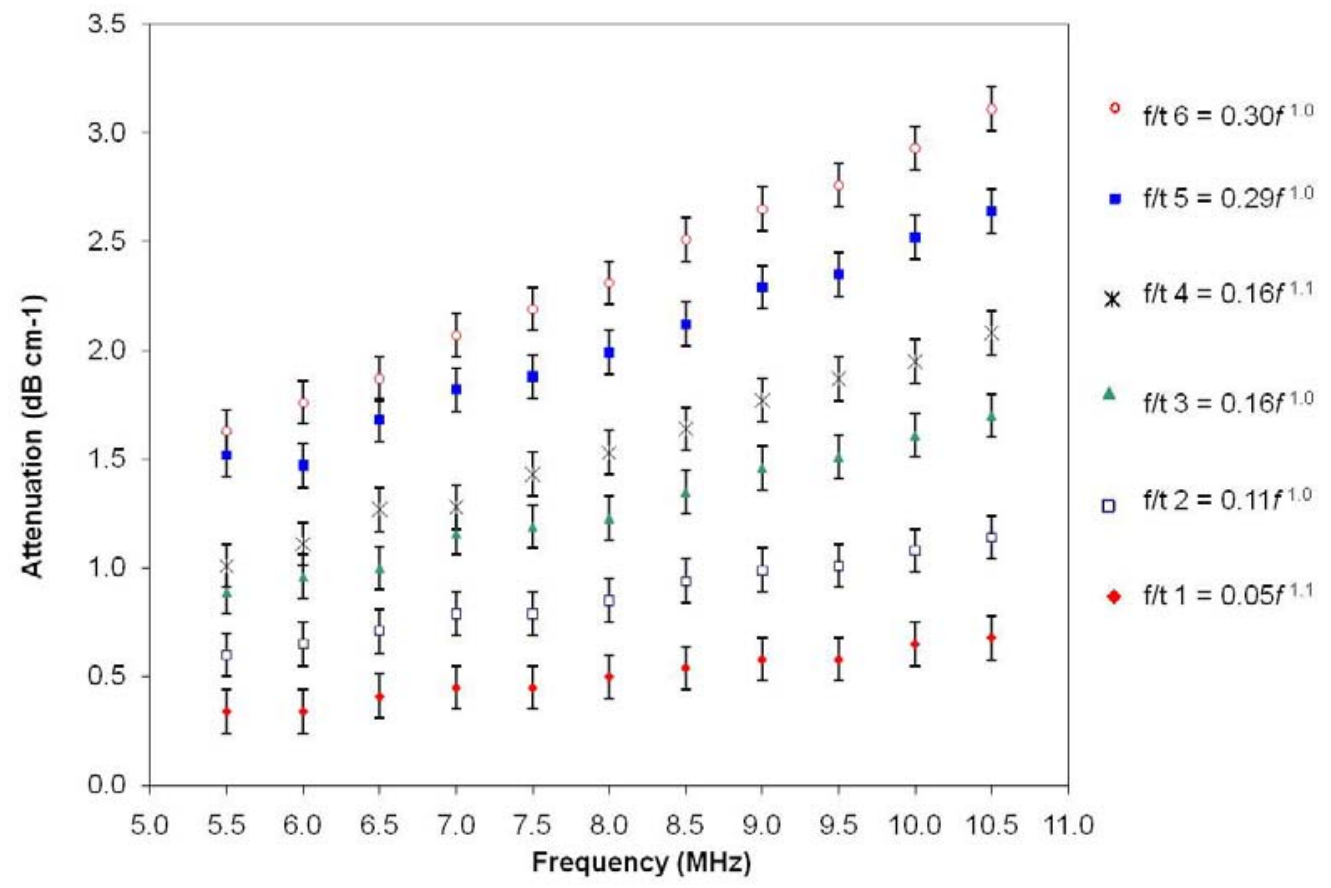

Fig. 4. Variation of the measured attenuation coefficient of the PVA-C samples in Batch-1 as a function of increasing number of freeze-thaw cycles over a frequency range from $5.5-$ $10.5 \mathrm{MHz}$.

The speed of sound and attenuation coefficients for the remaining batches of PVA-C samples obtained using the $3.5 \mathrm{MHz}$ and $7 \mathrm{MHZ}$ transducer are presented in Tables 2 and 3. 
The speed of sound of the samples containing the anti-bacterial agent $\mathrm{BC}$ were found to be approximately $2 \%$ higher than in PVA-C-only samples, while the actual concentration of the BC did not appear to have a significant effect on the speed of sound values for the three different concentrations. Furthermore, it was found that with the addition of the anti-bacterial agent, the PVA-C material's speed of sound was dependent on frequency, with the speed of sound values at $3.5 \mathrm{MHz}$ being higher than the speed of sound values measured at $7 \mathrm{MHz}$ (Table 2). The different concentrations of the anti-bacterial agent $\mathrm{BC}$ had a negligible effect on the attenuation of the samples (Table 3), while as expected the attenuation coefficients were lower at $3.5 \mathrm{MHz}$ compared to the values obtained at $7 \mathrm{MHz}$.

Table 2. Summary of speed of sound measurements for PVA-C samples across all three batch: (i) Batch-2 - containing PVA C with $\mathrm{BC}$ at three different concentrations $(0.46 \% \mathrm{wt}$, $0.92 \%$ wt and $1.4 \% \mathrm{wt})$, (ii) Batch-3 - containing PVA C with BC $(0.46 \% \mathrm{wt})$ with silicon carbide particles $(0.75 \% \% \mathrm{wt})$, and Batch-3 - containing PVA C with only silicon carbide particles $(0.75 \% \mathrm{wt})$. Measurements were carried out at two frequencies centered at 3.5 $\mathrm{MHz}$ and $7 \mathrm{MHz}$.

\begin{tabular}{|c|c|c|c|c|c|c|}
\hline \multirow{3}{*}{$\begin{array}{c}\text { Frequency } \\
\text { (MHz) }\end{array}$} & \multirow{3}{*}{$\begin{array}{c}* f / t \\
\text { number }\end{array}$} & \multicolumn{5}{|c|}{ Speed of sound $\left( \pm 5 \mathrm{~m} \mathrm{~s}^{-1}\right)$} \\
\hline & & \multicolumn{3}{|c|}{ Batch-2 } & \multicolumn{2}{|c|}{ Batch-3 } \\
\hline & & $\begin{array}{l}\text { Вс Conc } 1 \\
(0.46 \% w t)\end{array}$ & $\begin{array}{l}\text { Bc Conc } 2 \\
(0.92 \% w t)\end{array}$ & $\begin{array}{l}\text { Bc Conc } 3 \\
3(1.4 \% w t)\end{array}$ & $\begin{array}{l}\mathrm{SiC}+\mathrm{Bc} \\
\text { Conc } 3\end{array}$ & $\mathrm{SiC}$ \\
\hline \multirow[t]{3}{*}{3.5} & 2 & 1538 & 1550 & 1535 & 1529 & 1538 \\
\hline & 4 & 1548 & 1571 & 1562 & 1549 & 1528 \\
\hline & 6 & 1579 & 1576 & 1578 & 1561 & 1541 \\
\hline \multirow[t]{3}{*}{7} & 2 & 1525 & 1513 & 1507 & 1556 & 1542 \\
\hline & 4 & 1527 & 1525 & 1525 & 1570 & 1533 \\
\hline & 6 & 1530 & 1545 & 1528 & 1576 & 1576 \\
\hline
\end{tabular}

*(f/t number indicates the number of freeze thaw cycles that the sample has undergone) 
Table 3. Summary of attenuation coefficients for Batch 2 containing PVA-C samples containing $\mathrm{BC}$ at three different concentrations ( $0.46 \% \mathrm{wt}, 0.92 \% \mathrm{wt}$ and $1.4 \% \mathrm{wt})$, Batch-3 containing PVA C with BC $(0.46 \%$ wt $)$ with silicon carbide particles $(0.75 \% \mathrm{wt})$ and Batch3 containing PVA-C with silicon carbide particles $(0.75 \% \mathrm{wt})$ at a centre frequency of 3.5 $\mathrm{MHz}$ and $7 \mathrm{MHz}$.

\begin{tabular}{|c|c|c|c|c|c|c|}
\hline \multirow{3}{*}{$\begin{array}{c}\text { Frequency } \\
\text { (MHz) }\end{array}$} & \multirow{3}{*}{$\begin{array}{c}*_{f} / t \\
\text { number }\end{array}$} & \multicolumn{5}{|c|}{ Attenuation Coefficient $\left( \pm 0.03 \mathrm{~cm} \mathrm{~dB}^{-1} \mathrm{MHz}^{-1}\right)$} \\
\hline & & \multicolumn{3}{|c|}{ Batch-2 } & \multicolumn{2}{|c|}{ Batch-3 } \\
\hline & & $\begin{array}{l}\text { Bc Conc } 1 \\
(0.46 \% w t)\end{array}$ & $\begin{array}{l}\text { Bc Conc } 2 \\
(0.92 \% w t)\end{array}$ & $\begin{array}{l}\text { Вс Сопс } 3 \\
3(1.4 \% w t)\end{array}$ & $\begin{array}{l}\text { SiC }+B c \\
\text { Conc } 3\end{array}$ & $\mathrm{SiC}$ \\
\hline \multirow[t]{3}{*}{3.5} & 2 & 0.07 & 0.08 & 0.03 & 0.10 & 0.09 \\
\hline & 4 & 0.09 & 0.12 & 0.12 & 0.14 & 0.15 \\
\hline & 6 & 0.12 & 0.21 & 0.21 & 0.30 & 0.35 \\
\hline \multirow[t]{3}{*}{7} & 2 & 0.25 & 0.20 & 0.19 & 0.28 & 0.37 \\
\hline & 4 & 0.31 & 0.30 & 0.30 & 0.41 & 0.36 \\
\hline & 6 & 0.42 & 0.45 & 0.41 & 0.50 & 0.56 \\
\hline
\end{tabular}

*(f/t number indicates the number of freeze thaw cycles that the sample has undergone $)$ 
The $[\mathrm{PVA}-\mathrm{C}+\mathrm{SiC}+\mathrm{BC}]$ samples were found to also result in an increase in the speed of sound with increasing number of freeze-thaw cycles as shown in Table 2, and for the most part had higher speed of sound values compared to that of the PVA-C + SiC samples for both frequencies tested. The samples containing only silicon carbide particles did not follow the trend of increasing speed of sound with increasing numbers of freeze-thaw cycles; rather, a non-linear relationship was found, with values obtained after 2, 4 and 6 freeze-thaw cycles of 1538,1528 and $1541 \pm 5 \mathrm{~m} \mathrm{~s}^{-1}$, respectively. Both the $[\mathrm{PVA}-\mathrm{C}+\mathrm{SiC}+\mathrm{BC}]$ and $[\mathrm{PVA}-\mathrm{C}+$ SiC] samples had a higher attenuation coefficient than the PVA-C-only samples (Table 3), further demonstrating increasing attenuation coefficient with increasing number of freezethaw cycles.

\section{Mechanical characterization results}

The Young's Elastic Modulus and mechanical characterization results for the PVA-C vessel mimicking material are presented in this section. The different stress strain relationship of the [PVA-C + BC] samples in Batch-1 are shown in Fig. 5 (a) for the six freeze-thaw cycles. For each freeze-thaw cycle, an elastic hysteresis can be observed with the stress slightly greater during loading than during unloading, which can be seen for the [PVA-C $+\mathrm{BC}]$ sample test strip after 6 freeze-thaw cycles in Fig. 5 (b). This is an indication that not all of the energy is immediately recovered during the unloading phases and is characteristic viscoelastic behaviour, which is commonly associated with elastomeric materials. In order to calculate the Young's Elastic Modulus of the samples, the raw data from the loading portion of the different stress strain curves as in Fig. 5(a) is used. The Young's Elastic Modulus was derived from the linear portion of the loading portion corresponding to the $0-30 \%$ strain region of the stress strain curve. The relationship between the number of freeze-thaw cycles and the Young's Elastic Modulus thus determined is presented in Fig. 6 along with the speed 
of sound data for the [PVA-C $+\mathrm{BC}$ ] samples. The Young's Elastic Modulus can be seen to increase with increasing number of freeze/thaw cycles, with a slight leveling-off evident after $5 \mathrm{f} / \mathrm{t}$ cycles. The increase in the speed of sound with increasing number of freeze/thaw cycles, on the other hand, did not show any such leveling effect. Furthermore, it was found that after 2-freeze/thaw cycles the speed of sound and Young's Elastic Modulus corresponded to the values for healthy arterial vessel and so this was the chosen number of freeze/thaw cycles for producing the VMM. 

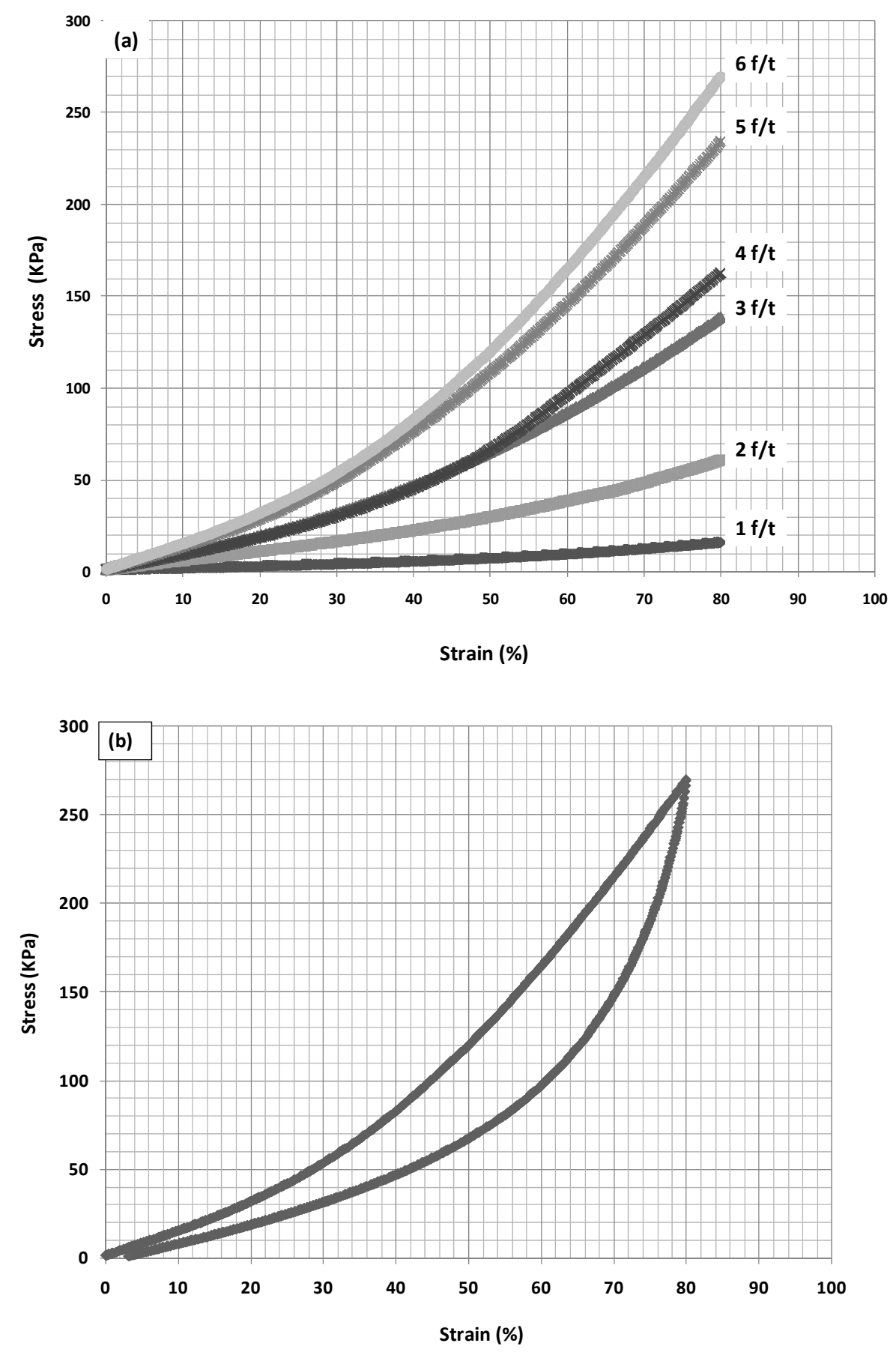

Fig. 5. (a) Loading stress strain curves for the 1 to 6 free-thaw cycles of the [PVA-C $+B C]$ samples. (b) Loading and Unloading Stress Strain curves for the [PVA-C + BC] sample after 6 freeze-thaw cycles. 


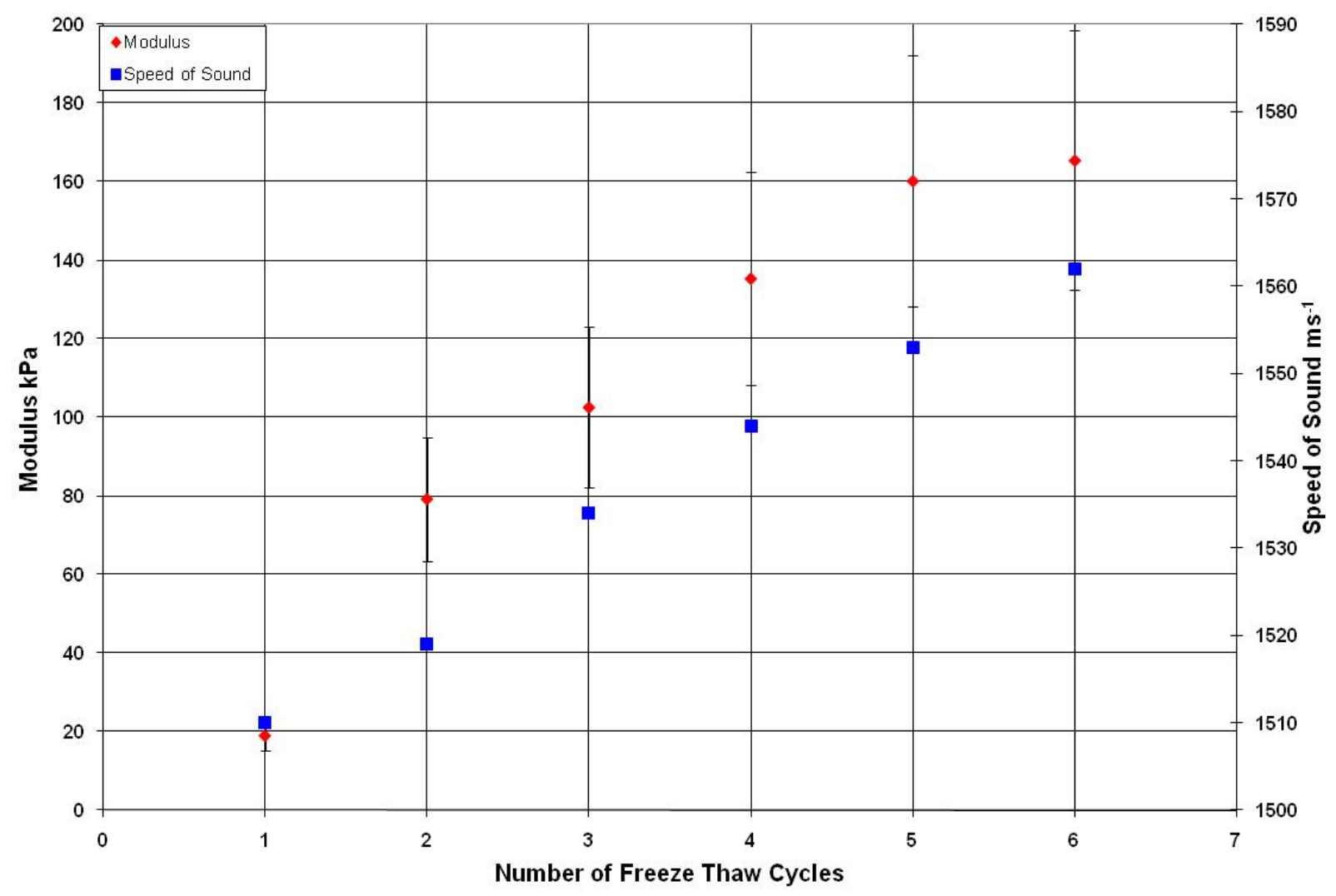

Fig. 6. The Young's elastic modulus derived from the linear portion of the slope of the loading curve and the corresponding Speed of Sound values for the [PVA-C + BC] samples for $1-6$ freeze-thaw cycles.

The time dependent characteristics of the PVA-C samples (viscoelasticity) were investigated by allowing a pause of 100 seconds at the maximum strain of $80 \%$ of the gauge length. The reduction in load was recorded over this period, before the load in the sample returned to its minimum value. Best fit curves were created for the viscoelastic data by applying a standard Maxwell model to the experimental stress relaxation data as presented in Fig. 7. As previously described by Ronan 2009 and Fung 1993, the Maxwell model represents the viscoelastic behaviour of a material by an analogy with a mass-spring-dashpot system with the spring and dashpot in series, as depicted inset in Fig. 8, where, E characterises the 
response of the spring and $\eta$ defines the viscous behaviour of the dashpot. The relationship between $\mathrm{E}$ and $\eta$ is given by the equation

$$
\tau=\frac{\eta}{E}
$$

where $\tau$ is the relaxation time for a mechanical system subjected to a controlled force. This provides an approximation of a constant time dependent characteristic of the PVA material. The equation of motion of the Maxwell model is

$$
\frac{d \varepsilon}{d t}=\frac{1}{E} \frac{d \sigma}{d t}+\frac{\sigma}{\eta}
$$

The equation is a linear combination of the perfectly elastic behaviour of Hooke's law and the viscous behaviour of a Newtonian fluid. A differential equation can be solved subject to defining experimental boundary conditions, in this case dictated by stress relaxation behaviour, allowing the equation to be developed to give Eq (3) which describes the logarithmic decremented stress decay with time when a test sample is held at a constant deformation.

$$
E(t)=E_{o} e^{\frac{-t}{\tau}}
$$

Where $E_{0}$ is the elastic modulus of the spring and $E(t)$, represents the stress relaxation modulus.

The experimental stress relaxation data was plotted against the Maxwell model for a 100s time interval, commencing with the initial stress value. The parameters (e.g. $\tau$ ) of the model were intuitively manipulated until the plot of the model closely matched that of the experimental data as shown in Fig. 7. This procedure was carried out for each individual data set for the materials for different freeze thaw cycles so that an average value of $\tau$ could be calculated. The values of $\tau$ plotted against the number of freeze flaw cycles is shown in Fig. 8. 


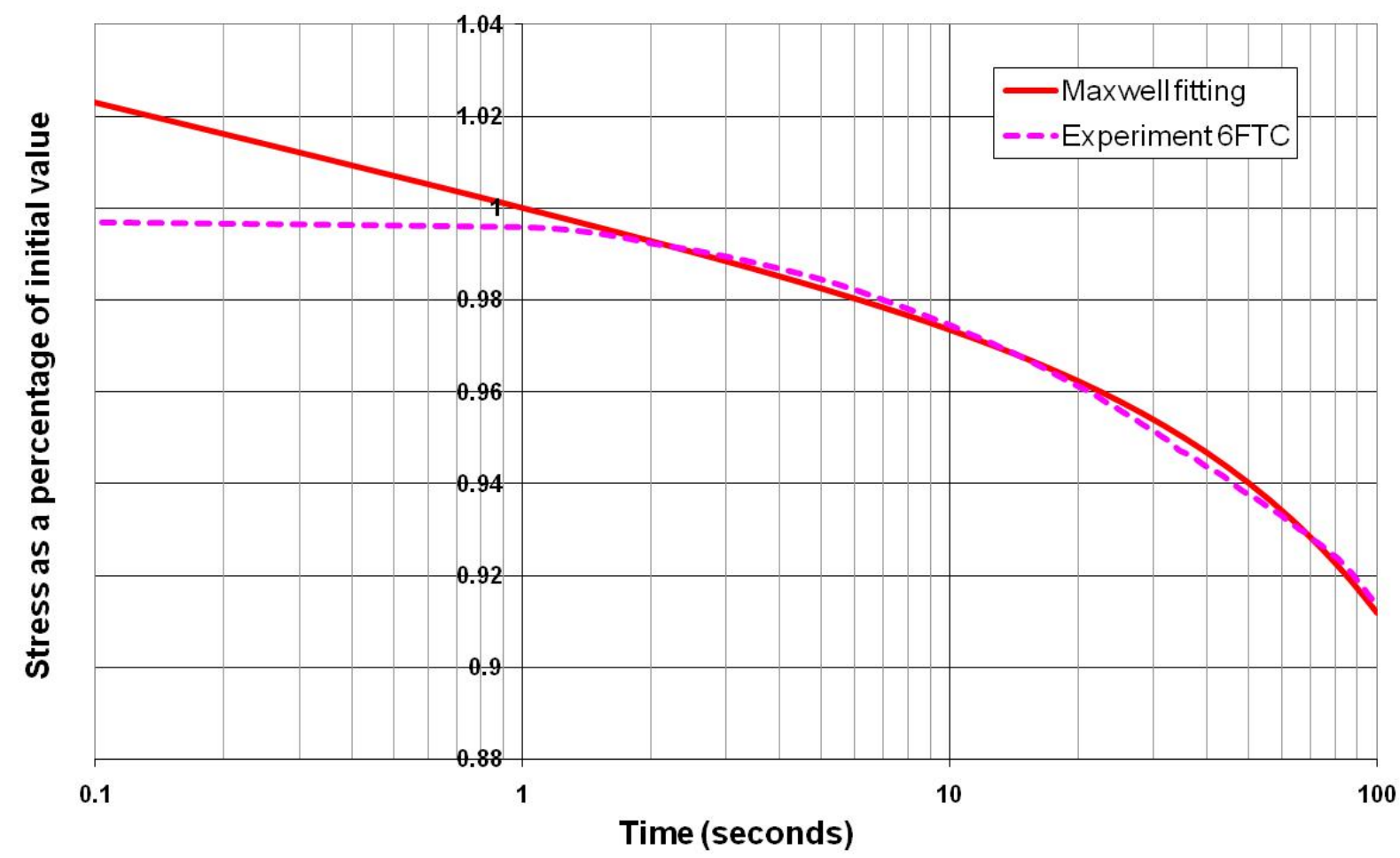

Fig. 7. Plot of experimental stress relaxation with the corresponding Maxwell model.

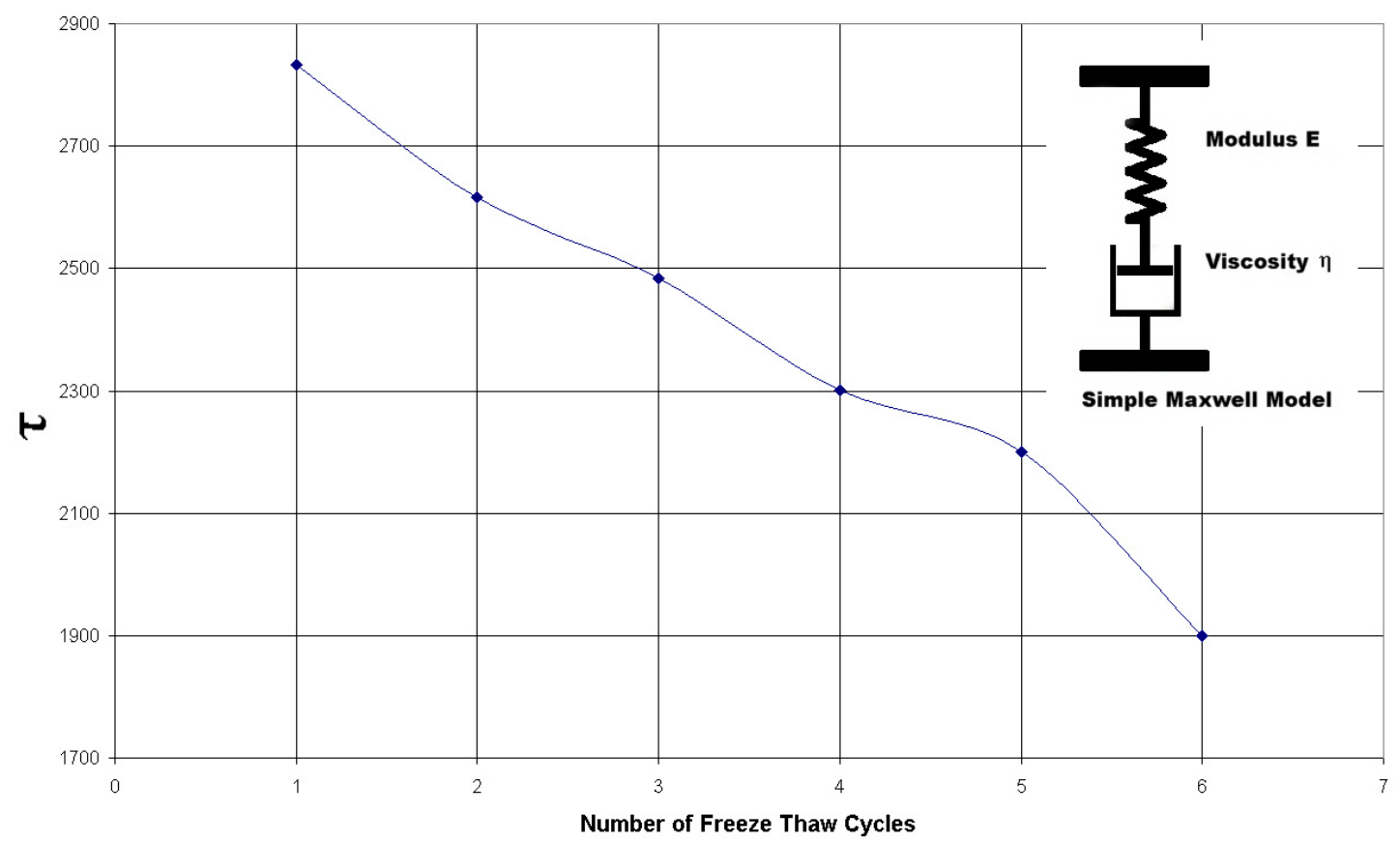

Fig. 8. Variation of the relaxation time parameter, $\tau$, derived from a Maxwell model, with increasing freeze-thaw cycles. 


\section{Basic Flow Simulation Results}

The walled phantoms were found to be more mechanically robust than the wall-less phantoms, with a maximum velocity of $40 \mathrm{~cm} \mathrm{~s}^{-1}$ in the unstenosed region, similar to that found in vivo, then increasing to maximum for example for the $70 \%$ stenosis of $325 \mathrm{cms}^{-1}$ at the stenosed region, achieved without rupturing in all of the walled phantoms except the phantom with the $85 \%$ stenosis, where a maximum velocity without rupturing of $25 \mathrm{~cm} \mathrm{~s}^{-1}$ in the unstenosed region was possible. The recorded velocities for each stenosis are presented in Table 4. Using a paired t-test, the maximum velocities recorded from wall-less and walled phantoms for the normal geometry, the $30 \%$ and $50 \%$ stenosis were compared. The mean maximum velocity \pm confidence interval, with corresponding $95 \%$ confidence intervals and p-values are presented in Table 4 . The results show that there is a significant difference between the wall-less and walled phantom measurements $(p<0.05)$ for all stenoses.

Table 4. Comparison of the maximum velocity $\left(\mathrm{V}_{\max } \pm 1.96(\mathrm{SE})\right)$ measured at the site of stenosis for the wall-less and walled phantoms at $40 \mathrm{~cm} \mathrm{~s}^{-1}$, with the corresponding $95 \%$ confidence intervals and $\mathrm{p}$ value.

\begin{tabular}{l|l|l|l|lc|l}
\hline \multirow{2}{*}{ Stenosis } & Phantom & Predicted $\boldsymbol{V}_{\max }$ & $\boldsymbol{V}_{\max }$ & 95\% Confidence Intervals & P value \\
& & $\left(\mathbf{c m ~ s}^{-\mathbf{1}}\right)$ & $\left(\mathbf{c m ~ s}^{-\mathbf{1}}\right)$ & & & \\
& & & & Lower & Upper & \\
\hline \multirow{2}{*}{ Normal } & Wall-less & 80 & $79 \pm 1$ & 77.2 & 80.4 & $<0.0001$ \\
& Walled & & $70 \pm 1$ & 68.2 & 71.6 & \\
$30 \%$ & Wall-less & \multirow{2}{*}{114} & $120 \pm 2$ & 117.0 & 125.4 & $<0.0001$ \\
& Walled & & $136 \pm 1$ & 132.5 & 138.5 & \\
& Wall-less & \multirow{2}{*}{160} & $197 \pm 1$ & 137.6 & 145.3 & $<0.001$ \\
& Walled & & $118 \pm 2$ & 113.9 & 122.5 & \\
\hline
\end{tabular}




\section{Discussion}

In this study, the acoustic and mechanical properties of PVA-C samples fabricated under a variety of conditions were characterized in order to investigate the use of this material as a vessel mimicking material in flow phantoms. In order to improve the material as a vessel mimic, an anti-bacterial agent and silicon carbide particles were added and the corresponding effects on the acoustic and mechanical properties of the material were determined. The ultimate aim of this study was to determine the required composition and number of freezethaw cycles to achieve acoustic and mechanical properties similar to those of the renal artery in vivo. The acoustic properties of vessels within the body can vary greatly from those of average soft tissues, which must be considered when specifying the acoustic properties of an ideal VMM (Duck et al. 1990). Furthermore, alterations in the tissue-composition of arteries due to increasing age and disease progression are associated with alteration in both acoustic and mechanical properties (Hoskins 2007). In this study, it was found that the speed of sound increased from 1507 to $1576 \pm 5 \mathrm{~m} \mathrm{~s}^{-1}$ with increasing the number of freeze-thaw cycles from one to six. The speed of sound for healthy arteries have previously been measured to vary from 1501- $1534 \mathrm{~m} \mathrm{~s}^{-1}$ and $1568-1616 \pm 25 \mathrm{~m} \mathrm{~s}^{-1}$ (Greenleaf et al., 1974; Duck 1990). For diseased arteries, speed of sound values ranging from 1526 to $1760 \mathrm{~m} \mathrm{~s}^{-1}$ have been reported (Duck et al. 1990; Greenleaf et al.1974). Considering the attenuation coefficient, Greenleaf et al. (1974) measured a value of $0.6 \mathrm{~dB} \mathrm{~cm}^{-1} \mathrm{MHz}^{-1}$ at $10 \mathrm{MHz}$ in healthy arteries, while Hoskins et al. (2007) combined the data from Fraser et al. (2006) and Lockwood et al. 1991 to give a single attenuation as a function of frequency (f) relationship of $1.026 \mathrm{f}^{1.121}$ for healthy arteries in the frequency range 5 to $56 \mathrm{MHz}$. The attenuation of diseased arteries is significantly higher than healthy arteries, with a mean of $11 \pm 4 \mathrm{~dB} \mathrm{~cm}^{-1} \mathrm{MHz}^{-1}$ but reaching $25 \pm 1 \mathrm{~dB} \mathrm{~cm}^{-1} \mathrm{MHz}^{-1}$ in the calcified regions of the artery (Saijo et al. 2004; Saijo et al. 1998). These reported values for both healthy and diseased arteries are considerably higher 
than those achieved in this study with PVA-C only samples, which had attenuation coefficients values of less than $0.06 \mathrm{~dB} \mathrm{~cm}^{-1} \mathrm{MHz}^{-1}$ at 3.5 and $7 \mathrm{MHz}$ for all numbers of freeze-thaw cycles investigated. However, an increase in attenuation coefficient was observed following the addition of the silicon carbide particles, which in a previous study were found to enhance both the backscatter and the attenuation (Dineley et al. 2006). However, it was observed in the current study that during the preparation of the samples, the silicon carbide particles did not remain evenly suspended in the sample during the freezethaw process. Various methods were attempted to overcome this problem, including cooling the gel to $60^{\circ} \mathrm{C}$ before introducing the particles, stirring the mixture for an additional hour before pouring into moulds, and using different amounts of silicon carbide. Although each method improved the natural suspension of the particles in the gel, the sinking and separation of particles within the sample was still a problem with increasing number of freeze-thaw cycles, where the silicon carbide particles invariably gravitated to the bottom of the sample. This resulted in samples having two very different layers: a top layer containing very few or no silicon carbide particles, and a bottom layer where the majority of the particles were located. When performing speed of sound measurements, sample scans from both layers were thus obtained, with the final speed of sound value for each sample taken as the mean of these two measurements. It was felt that this gravitation of the silicon carbide particles in the PVA-C samples of various freeze thaw cycles contributed a large amount of variation in these speed of sound measurements, which resulted in the PVA-C $+\mathrm{SiC}$ samples exhibiting an initial increase in speed of sound with an increasing number of freeze thaw cycles, with a decrease in the speed of sound following the sixth freeze thaw cycle. A similar trend was found in the repeat experiments that were carried out on this PVA-C mixture despite the various efforts to obtain uniform distribution of the particles with the sample. This trend of decreasing speed of sound with increasing freeze thaw cycles from four to six for PVA-C 
samples with silicon carbide particles was also found by Dineley et al. 2006, although it was not reported as being statistically significant.

Since PVA-C is hydrophilic and susceptible to proliferation of bacterial growth, it is desirable to have an anti-bacterial agent present in the PVA-C sample to prevent bacterial growth of the sample. Indeed, bacterial growth appeared on a number of PVA-C samples which did not contain any anti-bacterial agent after several days. Chu and Rutt (1997) used an anti-bacterial agent in their PVA-C samples and indicated that the agent changed the MR relaxometry properties of their samples; however, they did not quantify this change. The use of Benzalknonium Chloride (BC) in the current study stemmed from its use in a previous study, where it was observed to increase the lifetime of a TMM (Teirlinck et al. 1998). The addition of as little as $0.46 \% \mathrm{wt} \mathrm{BC}$ was observed to increase the speed of sound, although increasing this to $1.4 \%$ did not have any further effect.

As discussed in the introduction, one of the main disadvantages of PVA-C for use as a vessel mimicking material in ultrasound flow phantoms is its low attenuation coefficient. To address this shortcoming, Surry et al. (2004) added enamel paint to the PVA solution which resulted in an increase in the attenuation coefficient. However, Nadkarni et al. (2003) in an earlier study reported that the addition of the enamel weakened the PVA matrix, rendering it more susceptible to tear and unsuitable as a vessel mimicking material. Dineley et al. (2006) used silicon carbide particles to enhance the backscatter of the signal, thereby increasing the attenuation coefficient of the PVA-C material. In the current study, the sample which had speed of sound and attenuation coefficient values closest to the desired values was the [PVA$\mathrm{C}+\mathrm{SiC}$ ] sample (for which $\mathrm{c}=1538 \mathrm{~m} \mathrm{~s}^{-1}$ and $\alpha=0.35 \mathrm{~dB} \mathrm{~cm}^{-1} \mathrm{MHz}^{-1}$ ). Unfortunately, due to the sedimentation of the $\mathrm{SiC}$ particles during preparation and the resultant variability in material properties the use of silicon carbide particles was not deemed suitable for use in the production of a reproducible VMM. Consequently, the sample containing only the addition 
of $0.46 \mathrm{wt} \% \mathrm{BC}$ was used as the VMM. Furthermore, the use of 2 freeze-thaw cycles was deemed optimal as its speed of sound at $1538 \mathrm{~m} \mathrm{~s}^{-1}$ most closely matched that of healthy in vivo vessels. However, at $0.07 \mathrm{~dB} \mathrm{~cm}^{-1} \mathrm{MHz}^{-1}$, its attenuation coefficient was significantly lower than that found in vivo $\left(0.3-0.6 \mathrm{~dB} \mathrm{~cm}^{-1} \mathrm{MHz}^{-1}\right)$. The IEC 61685 standard specifies that the vessel wall in an ultrasound flow test object should reduce the signal by an amount less than the signal reduction caused by a layer of TMM having a thickness equal to the vessel diameter (i.d.). The PVA-C samples described here, with an attenuation of $0.07 \mathrm{~dB}$ $\mathrm{cm}^{-1} \mathrm{MHz}^{-1}$ (equal to $0.18 \mathrm{~dB} \mathrm{~cm}^{-1}$ at $2.5 \mathrm{MHz}$ ), results in a $0.035 \mathrm{~dB}$ loss through a $2 \mathrm{~mm}$ wall compared to a $0.925 \mathrm{~dB}$ loss through a $7.4 \mathrm{~mm}$ thickness ( equivalent to the i.d. of the lumen in the renal artery flow phantom) of TMM (IEC 2001). Therefore, the PVA-C vessel developed in the current study complies with this IEC standard.

The Young's elastic modulus of the PVA-C samples was found to increase with increasing number of freeze-thaw cycles, with a plateau of the Young's elastic modulus occurring after the 5th freeze-thaw cycle. This may suggest that the PVA-C material was approaching saturation point of the cryogel in terms of intermolecular cross-linking. This effect has been observed elsewhere (Chu and Rutt, 1997) and places an upper limit on Young's elastic moduli available for a given concentration of cryogel. The Young's elastic modulus values, which ranged from 19 to $165 \mathrm{kPa}$ in the current study, are similar to those obtained by Duboeuf et al. (2007) for $10 \%$ PVA-C concentration. For healthy arteries, a Young's elastic modulus of $70-100 \mathrm{kPa}$ was reported by Kawasaki et al. 1987, which was mimicked in the PVA-C samples here following 2 or 3 freeze-thaw cycles. The viscoelastic investigation revealed that the PVA-C material best fit a simple Maxwell model this model is one of the most basic models used to describe the relationship between stress and strain of tissue. The model is based on the interaction of a spring and a dashpot in series, and the response of the system to an applied force is described by the addition of both of these 
components in series by the addition of the function corresponding to the velocity of the spring and the velocity of the dashpot found by integration (Fung 1993).

The walled flow phantoms with the vessel mimic constructed using the PVA-C material with anti-bacterial agent (Batch 2) proved to be more mechanically robust than wallless phantoms which had the blood mimicking fluid in direct contact with the TMM, in terms of their ability to support a maximum velocity of $80 \mathrm{~cm} \mathrm{~s}^{-1}$ without rupturing. This result was to be expected as the TMM is more brittle than the PVA-C VMM and therefore more likely to rupture once jet velocities are produced due to the presence of the stenosis in the flow phantoms. This demonstrates the advantage of using walled phantoms, particularly when physiological flow conditions are used in anatomically-realistic phantoms. Previous studies using anatomically-realistic carotid arteries have also encountered problems with the vessel rupturing under conditions of high stenosis and high flow rates, while walled vessels were found to allow the development of more robust flow phantoms capable of withstanding physiological flow stress (Poepping et al. 2002; Poepping et al. 2004; Meagher et al. 2007). Despite the difficultly associated with developing robust flow phantoms which can withstand physiological flow stress it is nonetheless important that this is attempted as the purpose of developing these complex arbitrary geometries in the phantoms is to mimic the in vivo situation as closely as possible and thus produce realistic flow conditions.

Another interesting feature of the walled vessel phantoms constructed from PVA-C $+\mathrm{BC}$ was a marked reduction in the maximum velocity measured at the location of the stenosis compared to the wall-less phantom, this may be due to the expansion of the PVA C vessel in the walled vessel phantoms, thereby increasing the inner diameter and causing a corresponding drop in the maximum velocity. This flexibility and expansion would not be seen in a wall-less flow phantom as the TMM is rigid and holds the same geometry through 
the lifetime of the phantom unless it has been ruptured due to the excessive velocity of the BMF pumped through the phantom lumen as reported by Ramnarine et al. 2001.

Although only steady-state flow conditions were used in the current study, it can be expected that the PVA-C vessel will have a significant effect on the maximum velocity measurements under conditions of pulsatile flow. In this situation, the flow system's pump would produce pressure waves which travel down the vessel at a speed determined by the elastic properties of the vessel wall. Since PVA-C is a visco-elastic material, reflections of the pressure waves would occur at the stenosis and bending of the vessel. If the material is very elastic a second peak on the flow waveform could occur (IPEM, 1994). These false secondary waves could be removed by the use of a high out-flow impedance (Hoskins et al. 1989; Dineley et al. 2006). 


\section{Conclusions}

Through a combination of additives and freeze/thaw cycling, it is possible to produce PVA-C samples which exhibit similar acoustic and mechanical properties to those of human arteries and consequently this material is a suitable vessel mimicking material for use in anatomically-realistic flow phantoms. In the current study, a sample containing PVA-C with $0.46 \mathrm{wt} \%$ of the anti-bacterial agent, Benzalkonium Chloride processed with two freeze-thaw cycles was found to produce the optimal acoustic and mechanical properties. The mechanical characterisation of this material showed that it exhibited properties similar to that of arteries in vivo. When used to form the vessels in a walled flow phantom, it was found that higher degrees of stenoses and higher flow velocities could be accommodated before vessel rupturing, demonstrating the benefits of this approach to flow phantom construction.

\section{Acknowledgements}

The authors wish to thank Peter Hoskins and James Blake (University of Edinburgh) for the use of the SAM system and technical assistance. This work was supported by the Technological Sector Research Strand 1 Scheme, HEA and the TERs 2005 and CABS 2007 Schemes, Research Support Unit, Dublin Institute of Technology. CMM would like to acknowledge funding from the British Heart Foundation (PG/07/107) and the advice and use of physical test facilities provided by Dr Thomas Alshuth and Peter Erren of the Deutsches Institut für Kautschuktechnologie e.V. (Hannover). 


\section{References}

Bale-Glickman, J., Selby K., Saloner D, and Savas O "Experimental flow studies in exactreplica phantoms of atherosclerotic carotid bifurcations under steady input conditions." J Biomech Eng 2003, 125(1): 38-48.

Browne, J. E., Ramnarine, K V, Watson, A J and Hoskins, P R"Assessment of the acoustic properties of common tissue-mimicking test phantoms." Ultrasound Med Biol 2003 29(7): 1053-60.

Chu, K. C. and Rutt B. K "Polyvinyl alcohol cryogel: an ideal phantom material for MR studies of arterial flow and elasticity." Magn Reson Med 1997 37(2): 314-9.

Cournane S, Cannon L, Browne J E and Fagan A J "Assessment of the accuracy of an ultrasound elastography liver scanning system using a PVA-cryogel phantom with optimal acoustic and mechanical properties" Physics Med Biol 2010 55: 5965-5983.

Dabrowski, W., Dunmore-Buyze J, Cardinal HN, and Fenester A"A real vessel phantom for flow imaging: 3-D Doppler ultrasound of steady flow." Ultrasound Med Biol 2001 27(1): 135-41.

Dabrowski, W., Dunmore-Buyze J, Rankin RN, Holdsworth DW and Fenester A "A real vessel phantom for imaging experimentation." Med Phys 1997 24(5): 687-93.

Dineley, J.,Meagher S, Poepping TL, Mc Dicken WN, and Hoskins PR, "Design and characterisation of a wall motion phantom." Ultrasound Med Biol 2006 32(9): 134957.

Duboeuf, F, Liebgott, H, Basarab, A, Brusseau, E, Delachartre, P and Vray, D Static Mechanical Assessment of Elastic Young's Modulus of Tissue Mimicking Materials Used for Medical Imaging. Conf Proc IEEE Eng Med Biol Soc, 2007, 3450-3.

Duck, F. A. Physical Properties of Tissue: A Comprehensive Reference Book. 1990 London, Academic Press Inc. 
Fraser, K. H., Poepping T. L.,McNeilly A, Megson IL and Hoskins PR "Acoustic speed and attenuation coefficient in sheep aorta measured at 5-9 MHz." Ultrasound Med Biol 2006 32(6): 971-80.

Fromageau, J., Brusseau E., Vray D, Gimenez G and Delachartre P "Characterization of PVA cryogel for intravascular ultrasound elasticity imaging." IEEE Trans Ultrason Ferroelectr Freq Control 2003 50(10): 1318-24.

Fromageau, J., Gennisson J. L., Schmitt C, Maurice RL, Mongrain R and Cloutier G "Estimation of polyvinyl alcohol cryogel mechanical properties with four ultrasound elastography methods and comparison with gold standard testings." IEEE Trans Ultrason Ferroelectr Freq Control 2007 54(3): 498-509.

Fung Y.C. "Biomechanics: Mechanical properties of living tissue 2nd edn1993 (New York: Springer).

Greenleaf, J F, Duck, F A, Samayoa, W F and Johnston, S A Ultrasonic Data Acquisition and Processing System for Athersclerotic Tissue Characterization IEEE Ultrason Symp 1974.

Hoskins, P. R. "Physical properties of tissues relevant to arterial ultrasound imaging and blood velocity measurement." Ultrasound Med Biol 2007 33(10): 1527-39.

Hoskins, P. R. "Simulation and validation of arterial ultrasound imaging and blood flow." Ultrasound Med Biol 2008 34(5): 693-717.

Hoskins, P. R., T. Anderson, and Mc Dicken WN"A computer controlled flow phantom for generation of physiological Doppler waveforms." Phys Med Biol 1989 34(11): 170917.

International Electrotechnical Commission Ultrasonics - Flow measurement systems: Flow test object. G. International Electrotechnical Commission, 2001 Switzerland. 
IPEM (1994) Report No. 70, P R, Evans, J A and Sheriff, S eds, Testing of Doppler Equipment. IPEM, York.

ISO-7743 Rubber, vulcanized or thermoplastic - Determination of compression stress-strain properties. (2008) (Sweden)

Kawasaki, T., Sasayama S.,Yagi S, Asakawa T and Hirai T "Non-invasive assessment of the age related changes in stiffness of major branches of the human arteries." Cardiovasc Res (1987). 21(9): 678-87.

King, D. M., M. Ring,Moran CM and Browne JE "Development of a range of anatomically realistic renal artery flow phantoms." Ultrasound Med Biol (2010) 36(7): 1135-44.

Law, Y. F., Johnston K. W., Routh HF and Cobbold RS "On the design and evaluation of a steady flow model for Doppler ultrasound studies." Ultrasound Med Biol (1989) 15(5): 505-16.

Lockwood GR, Ryan LK, Hunt JW, Foster FS. Measurement of the ultrasonic properties of vascular tissues and blood from 35-65 MHz. Ultrasound Med Biol, 1991 (17), $653-666$.

Meagher, S., Poepping T. L., Ramnarine KV, Black RA and Hoskins PR "Anatomical flow phantoms of the nonplanar carotid bifurcation, part II: experimental validation with Doppler ultrasound." Ultrasound Med Biol 2007 33(2): 303-10.

Nadkarni, S K, Austin, H, Mills, G, Boughner, D and Fenster, A A Pulsating Coronary Vessel Phantom for Two- and Three-Dimensional Intravascular Ultrasound Studies. Ultrasound in Medicine \& Biology, 2003 29(4), 621-8.

Poepping, T. L., Nikolov H. N., Rankin RN, Lee M and Holdsworth DW "An in vitro system for Doppler ultrasound flow studies in the stenosed carotid artery bifurcation." Ultrasound Med Biol 2002 28(4): 495-506. 
Poepping, T. L., Nikolov H. N., Thorne ML and Holdsworth DW "A thin-walled carotid vessel phantom for Doppler ultrasound flow studies." Ultrasound Med Biol 2004 30(8): 1067-78.

Ramnarine, K. V., Anderson T. And Hoskins PR"Construction and geometric stability of physiological flow rate wall-less stenosis phantoms." Ultrasound Med Biol 2001 27(2): 245-50.

Ramnarine, K. V., Nassiri D. K., Hoskins PR and Lubbers J"Validation of a new bloodmimicking fluid for use in Doppler flow test objects." Ultrasound Med Biol 1998 24(3): 451-9.

Rickey, D. W., Picot P. A., Christopher DA and Fenester A A wall-less vessel phantom for Doppler ultrasound studies." Ultrasound Med Biol 1995 21(9): 1163-76.

Ronan S, PhD Thesis, A Novel Approach to Predicting the Lifetime of Elastomers Undergoing Stress Relaxation, 2009 Dublin Institute of Technology

Saijo, Y., Miyakawa T., Sasaki H, Tanaka M and Nitta S"Acoustic properties of aortic aneurysm obtained with scanning acoustic microscope." Ultrasonics 2004 42: 695698.

Saijo, Y., Sasaki H., Okawai H, Nitta S and Tanaka M "Acoustic properties of atherosclerosis of human aorta obtained with high-frequency ultrasound." Ultrasound in Medicine \& Biology 1998 24: 1061-1064.

Shortland, A. P. and T. Cochrane "Doppler spectral waveform generation in vitro: an aid to diagnosis of vascular disease." Ultrasound Med.Biol. 1998 15(8): 737-748.

Surry, K. J., Austin H. J., Fenester A and Peters TM et al. "Poly(vinyl alcohol) cryogel phantoms for use in ultrasound and MR imaging." Phys Med Biol 2004 49(24): 552946. 
Teirlinck, C. J., Bezemer R. A., Kollmann C, Lubbers J, Hoskins PR, Ramnarine KV, Fish P, Fredeldt KE and Schaarschmidt UG "Development of an example flow test object and comparison of five of these test objects, constructed in various laboratories." Ultrasonics 1998 36(1-5): 653-60.

Wan, W. K., Campbell G, Zhang ZF, Hui AJ, Boughner DR"Optimizing the tensile properties of polyvinyl alcohol hydrogel for the construction of a bioprosthetic heart valve stent." J Biomed Mater Res 2002 63(6): 854-61. 